\title{
Maternidad y poder en la dramaturgia limeña contemporánea ${ }^{1}$
}

\author{
Natalia Torres Vilar \\ Universidad de Lima \\ Pontificia Universidad Católica del Perú
}

Recibido: 5 de mayo de 2014 / Aceptado: 30 de agosto de 2014

Los roles masculinos y femeninos han venido replanteando su lugar en la sociedad, y ello ha generado dificultades para equilibrar el derecho de la mujer sobre la procreación sin llegar al abuso del poder sobre la misma. A través de un diseño cualitativo y asumiendo que un producto cultural, como es el cuerpo dramatúrgico de un lugar, visibiliza las complejidades de los procesos psicológicos de una sociedad, en el presente trabajo se explora cómo se despliegan las subjetividades y asociaciones entre maternidad y poder en algunas piezas de la dramaturgia limeña contemporánea. Se acuña el término de hombre fertilizante y se discuten algunas lineas encontradas en este cuerpo literario, como el poder nutricio de la mujer, las dinámicas de pareja vinculadas al abuso del poder, la envidia entre géneros y los desplazamientos de esta lucha de poder hacia los hijos.

hombre fertilizante / poder nutricio / mirada materna

\section{Motherhood and power in the dramatic literature in Lima}

Gender roles have been redefining their place in society, and this has generated difficulties regarding the equilibrium between women's right to procreate and the abuse of their power over this. Using a qualitative design and assuming that a cultural product, such as the dramatic literature of a certain place, visibilizes the complexities of the psychological processes of a society, this research explores the ways in which subjectivities and associations between maternity and power are displayed in a group of texts of contemporary playwrights in Lima. The concept of the fertilizing man is suggested and some topics found throughout this literary corpus are discussed, such as women's nutritious power, couple dynamics related to the abuse of power, the envy between the genders and the displacements of this battle for power, onto the descendence.

\section{fertilizing man / nutritious power / maternal gaze}

1 Este trabajo ofrece uno de los diversos temas que forman parte del análisis realizado para la tesis doctoral La participación de la madre en la inscripción del orden simbólico en algunos textos de dramaturgia limeña contemporánea (Torres, 2012), presentada en la Pontificia Universidad Católica del Perú (PUCP), con el apoyo del Vicerrectorado de Investigación.

Correo electrónico: ntorres@correo.ulima.edu.pe 
En las últimas décadas los roles masculinos y femeninos han venido replanteando su lugar en la sociedad. Por su parte, la mujer interviene cada vez más en las esferas políticas y laborales, y ha desarrollado un cada vez mayor control de su erotismo. El día de hoy es posible que la mujer valide su derecho de maternidad aun en ausencia de una pareja. Todo esto se replantea también, sin duda, a nivel de motivaciones, temores y esperanzas inconscientes. Aparece así un fenómeno: la dificultad para equilibrar el derecho de la mujer sobre la procreación sin llegar al abuso del poder sobre la misma.

Considerando la dramaturgia como una manifestación cultural que permite pensar la relación entre el hombre y el mundo, y a partir de la premisa psicoanalítica de que toda creación literaria es el reflejo de un inconsciente colectivo canalizado a través de su autor, exploremos cómo se despliega este fenómeno en algunas piezas de la dramaturgia limeña contemporánea.

En los vínculos de pareja presentados en las obras de nuestra dramaturgia contemporánea, llama la atención la marcada lucha genérica teñida de permanentes intentos de apoderarse de los atributos del otro, en una competencia y envidia de doble vía. Como lo había postulado Horney (1980), la contraparte de la envidia del pene en la mujer bien puede ser, en el hombre, la envidia de la función reproductiva y nutricia de la mujer.

Las obras de nuestra dramaturgia plantean que dentro del orden de la sociedad en la que vivimos es el hombre quien ostenta un poder social indiscutible. Un ejemplo de esto lo encontramos en Respira (Adrianzén, 2009), cuando un personaje le dice a otro: "Felipe te quiere y será un buen marido. Qué más puede pedir una mujer" (p. 32). Tenemos otro ejemplo en Casualmente de negro (Kirchhausen, 1990, archivo electrónico ${ }^{2}$ ), cuando el padre le dice a su hijo mientras maltrata a su hija: "Aprende a ser hombre. ¡Así se trata a las mujeres!".

La marginación de la mujer — su falta de lugar en la estructura dominante- se evidencia, por ejemplo, en el siguiente comentario de Damián en Números reales (Dumett, 1999), quien desde su delirio nos dice: "[...] alguien en el futuro dibujaría todos los fenómenos del universo afectándose unos a otros. [...] Y en el fondo de este dibujo se vería un agujero negro. Un agujero negro visto por una mujer asustada" (p. 349). Este fragmento nos recuerda la concepción lacaniana de la mujer como un significado sin significante, aquello que descompleta la estructura dominante en tanto no está representada en ella.

2 Agradezco la gentileza de Maritza Kirchhausen al permitirme compartir el archivo electrónico de su obra. 
Ante esta posición, los personajes femeninos se ubican, mayoritariamente, de dos formas: tienden a rebelarse y a no querer ajustarse a un orden simbólico y social dominante, o se ubican, sacrificialmente, en el lugar que el orden les ha asignado. Pero siempre envidiando la libertad y poder que posee el hombre.

Según Lacan, el hijo siempre representa para la madre un sustituto del falo simbólico que a ella le falta. Pero este sustituto nunca satisface realmente, pues el deseo del falo persiste aun después de tener el hijo. Esto da lugar, a veces, a relaciones simbióticas en donde la madre no se resigna a renunciar a su poder sobre sus hijos, como lo evidencia María, personaje central de Cristo light (Adrianzén, 2000):

La naturaleza se equivocó con las madres. Debería dejar que los hijos se queden dentro todo el tiempo que una quiera. Solo una sabe cuándo es momento de echarlos a esta porquería de mundo. [...]. No me habría importado engordar y engordar contigo con tal de ahorrarte tantas desgracias (p. 44).

Este ejercicio de poder sobre los hijos es bien graficado por Mario en Respira (Adrianzén, 2009):

Todo, absolutamente todo, es agua. Nuestro cuerpo, el aire que res- piramos, seres que nos rodean, el planeta en que vivimos y casi con certeza otros mundos aún desconocidos. Por algo los científicos afirman que solo donde existe agua puede existir vida, aunque siempre se olviden de completar la frase: vida y también muerte (p. 29).

Un buen grupo de personajes maternos en nuestra dramaturgia son, en efecto, sumamente sobreprotectoras. Sin embargo, para poder mantener el dominio total sobre los hijos, el padre debe ser marginado o rechazado. Es tal vez por esto que el abandono paterno es un tema central en nuestras obras, en donde muchas de las veces observamos a una madre interfiriendo con el desempeño del rol paterno. En este sentido, las madres tienden a agredir a sus parejas, bajo el pretexto de estar decepcionadas. Estas devaluaciones pueden ser muy intensas, como dice Patricia en El nido de las palomas (Adrianzén, 1999, archivo electrónico $\left.{ }^{3}\right)$ : “[...] no me quedará más remedio que criarlo. $Y$ decirle que su padre fue el último conchito de la probeta más triste del banco de semen más pobre de la nación más subdesarrollada del mundo".

El otro lado de las tramas es que el hombre también parece envidiar a la mujer, en particular su capacidad nutricia y procreadora, como eviden-

3 Agradezco la gentileza de Eduardo Adrianzén al permitirme compartir el archivo electrónico de su obra. 
cia Damián en Números reales (Dummett, 1999):

Un día, un hombre se tragó un grano de arena. Pasó el tiempo y se dio cuenta de que una perla había comenzado a crecer en su estómago. Empezó a cultivarla. [...]. Esperaba con impaciencia el momento en que la perla hubiera crecido lo suficiente para vomitarla ante las miradas sorprendidas de todos. Pero también tenía miedo. Miedo de haber votado su única perla y que no le volviera a crecer otra nunca más (p. 369).

Como se desprende de la cita anterior, un tema interesante dentro de nuestra dramaturgia son las constantes alusiones a las tendencias incorporativas. Patricia, en El nido de las palomas (Adrianzén, 1999, archivo electrónico), por ejemplo, nos dice: "Tirar y estar embarazada son las dos únicas formas de tener a un hombre dentro de una".

La envidia surge de la falta, y por eso nos fragiliza siempre. Y la envidia hace que hombre y mujer se agredan, en un interjuego que llega en muchas de nuestras obras a extremos dramáticos. Para graficar este intercambio de agresiones, citemos a Patricia, quien, en $E l$ nido de las palomas, afirma:

Los que endiosaron la maternidad son los hombres. Imagínate a los cavernícolas apestosos saliendo en grupo a cazar un mamut. [...]. Ellos se van a cazar y ellas se quedan in- ventando la cerámica, las ciudades y la agricultura. Luego de tres o cuatro días y unos diez muertos la mayoría por lentos, miopes y huevones, según Darwin- los cazadores regresan a la cueva justo en el momento que la mujer abre las piernas para que salga un hombrecito nuevo. Y lo hace ella solita, mientras que el pobre pitecántropo con las justas ha podido traer una docena de conejos, y entre varios. Conclusión: si una mujer podía dar vida tan fácilmente, también podía quitarla. Eso les dio pánico. Entonces no les quedó más remedio que volvernos diosas. $\mathrm{Y}$ al volvernos diosas nos agarraron de cojudas, ya que nada le gusta más a un hombre que tomarle el pelo a su dios (Adrianzén, 1999, archivo electrónico).

La mujer, entonces, envidia el poder social del hombre, y la maternidad y la capacidad nutricia se convertirán en su arma de lucha, sintiendo que ese poder tiene que ser arrebatado del hombre. Mónica, embarazada, en El nido de las palomas, se siente investida y fertilizada por su esposo, y en el relato de su sueño nos hace entender que equipara esta situación, inconscientemente, con la mirada de validación materna.

Estoy frente a la ventana y veo un árbol creciendo sobre una azotea. [...]. Desde allí me mira Raúl. [...]. Cuando al fin sus ojos tropiezan con los míos, yo me convierto en ese árbol plantado en la azotea [...] 
y mis brazos son ramas cargadas de frutos, y a la vez son cordeles y a la vez son sueños. Mientras el perro ladra, Raúl empieza a sollozar. Pero ya no me importa. No me importa nada. Y me quedo tranquila, muy tranquila (Adrianzén, 1999, archivo electrónico).

Parecería ser que lo que la hace sentir poderosa y en control es la sensación de dominio que otorga la mirada materna (Lacan, 1971), revivida en el deseo fertilizante de su esposo. Su hijo es su falo, la interiorización de su empoderamiento; la trama de un juego de identificaciones en la cual el bebé es tanto ella en su necesidad como el padre en su capacidad generativa; la amalgama de contenidos orales y fálicos.

La maestría y control del cuerpo, para Lacan -el falo, para Freud-, terminan depositándose en la fertilización en la mujer, para la que necesita al hombre, y una vez que ha logrado ese dominio, su mirada no parece importar de la misma manera. Los personajes femeninos de muchas obras parecen reconocer que el hombre tiene algo que ellas necesitan y engullen. Martín, en Entonces Alicia cayó (De Althaus, 2011), nos describe esta situación: "Cuando llegan los días fértiles te conviertes en una mantis religiosa [...]. La araña esa que se come al marido mientras copulan. $\mathrm{Y}$ yo en un pene que camina, o un saco de espermatozoides..." (p. 31).
La utilización del hombre fertilizante se nos presenta también en Función velorio (Miyashiro, 2001). En esta obra Clara está embarazada. Su esposo le pide que cierre los ojos y vea colores, puntos y líneas:

Cuando la línea ha madurado, se convierte en lo que siempre quiso ser [...]. Una línea lila va inventando una mujer con los cabellos que no se cortó nunca. Tiene cara de virgen, pero hace el amor a diario con un koala que solo sabe decir palabras dulces... El koala es otra línea y su color no importa. Nunca importó. [...]. Ahora está embarazada y su barriga es blanca. Ahora el koala ha dejado de ser dulce, ahora es un mamífero grotesco y ahora sí tiene color, muchos colores, demasiados colores (p. 397).

La mirada materna, entonces, parece ser el falo simbólico que completa cualquier falta. Siguiendo a Lacan, las madres de la dramaturgia limeña contemporánea buscan reeditar con sus parejas el descubrimiento de maestría corporal del bebé cuando este, a través de la mirada de su madre, observa su reflejo en el espejo. De este mismo modo, el hombre fertilizante debe otorgarle a la mujer, a través de su mirada deseante, esa maestría corporal representada en el embarazo. La mujer ahora es el reflejo de su propia madre omnipotente, y se siente capaz de prescindir del hombre en su vida $-y$ hacer prescindir 
a sus hijos de una figura paterna- de modos omnipotentes. Si bien Freud planteaba con claridad la repetición de la propia trama edípica no resuelta en los vínculos adultos de pareja, en este trabajo destacamos la importancia de no perder de vista que lo que se revive también, a modo de reparación, es el vínculo diádico inicial con la madre. Estamos, entonces, de acuerdo con Lacan, en cuanto para él el sujeto siempre desea a la madre (Evans, 1997), con independencia del sexo.

En relación con la mirada materna, podemos agregar que La Patria, personaje de Diecisiete camellos (Adrianzén, 2011), está cansada de estar de perfil. Los ciudadanos se quejan de que nunca pueden verla de frente: "No tienes cara. No nos miras. Ni siquiera sabemos por qué eres una mujer". Vinculamos todo ello con las dificultades que se generan, según Benjamin (1996), en el reconocimiento que la madre debe otorgarle a su bebé durante los procesos de separación e individuación, si ella no tiene una identidad independiente. En este sentido, la dificultad que encuentran los personajes maternos para conservar su rol como mujer, junto al de madre, nos parece ser clave para comprender el establecimiento de las relaciones simbióticas que establecen con sus hijos y las posteriores complicaciones para validar la Ley paterna. Solo son en tanto existen en la dupla con su bebé y, posteriormente, con su hijo. Sin haberse recono- cido primero a ellas mismas, las posibilidades de reconocer a otros (su bebé primero, luego el lugar del Nombredel-Padre) disminuyen.

En general, se puede afirmar que en las obras de la dramaturgia limeña contemporánea parece destacar el hecho de que a los personajes maternos se les dificulta renunciar a la sensación de omnipotencia que su maternidad les ha otorgado, pues esto implica renunciar al poder que solo así el orden social predominante les permite.

Olivier (1987) nos dice en su libro Los hijos de Yocasta que el amor es la tentativa de anular la diferencia y la falta, de renunciar a lo individual y de reencontrar la fantasía primitiva de la unidad con la madre omnipotente. Sin oponernos a este planteamiento, en estas páginas hemos puesto de relieve que, más que la simbiosis, las madres de la dramaturgia limeña reeditan con sus parejas el descubrimiento de maestría corporal del bebé. Es decir, buscan retomar su propio proceso inconcluso de separación e individuación. Este intento tiende a terminar de modos radicales: una vez poseedora de esta maestría y dominio, la mujer tiende a sentirse capaz de prescindir del hombre en su vida, y de hacer prescindir a sus hijos de una figura paterna. Con esto se establece la simbiosis entre ella y sus hijos, y su omnipotencia dificulta, una vez más, la separación. Se reinicia así el círculo vicioso que coloca siempre más allá la identidad individual. Con- 
cordamos con Olivier (1987), entonces, cuando concluye lo siguiente:

La existencia de la mujer hace indispensable la desacralización de la Madre, cuyo reinado engendra la misoginia del hombre. [...]. Es indispensable que las mujeres se den cuenta de que si siguen conservando el poder ante su hijo se verán alejadas automáticamente de todo otro poder (p. 249).

\section{RefERENCIAS}

Adrianzén, E. (1999). El nido de las palomas. Inédito.

Adrianzén, E. (2000). Cristo light. Muestra, I (2), 10-53.

Adrianzén, E. (2009). Respira. En Ponemos tu obra en escena. Segundo Concurso de Dramaturgia Peruana 2008 (pp. 15-77). Lima: Asociación Cultural Peruano Británica.

Adrianzén, E. (2011). Diecisiete camellos. En L. Proaño \& P. Encinas, Dramaturgia Ecuador-Perú (pp. 313-340). Lima: Universidad Científica del Sur.

Benjamin, J. (1996). Los lazos del amor. Buenos Aires: Paidós.

De Althaus, M. (2011). Entonces Alicia cayó. En Ponemos tu obra en escena.
Tercer Concurso de Dramaturgia Peruana 2010 (pp. 19-108). Lima: Asociación Cultural Peruano Británica.

Dumett, R. (1999). Números reales. En R. Ángeles \& J. Castro Urioste (Eds.), Dramaturgia peruana (pp. 335-401). Lima: Latinoamericana.

Evans, D. (1997). Diccionario introductorio de psicoanálisis lacaniano. Buenos Aires: Paidós.

Horney, K. (1980). Psicología femenina. Madrid: Alianza Editorial.

Kirchhausen, M. (1990). Casualmente de negro. Inédito.

Lacan, J. (1971). El estadío del espejo. En Escritos 1 (pp. 5-35). Buenos Aires: Siglo XXI.

Miyashiro, A. (2001). Función velorio. En R. Ángeles \& G. Luque (Eds.), Dramaturgia peruana II (pp. 489516). Lima: Latinoamericana.

Olivier, Ch. (1987). Los hijos de Yocasta. México, D. F.: Fondo de Cultura Económica.

Torres, N. (2012). La participación de la madre en la inscripción del orden simbólico en algunos textos de dramaturgia limeña contemporánea. (Tesis doctoral). Pontificia Universidad Católica del Perú. Lima, Perú. 
